\title{
WILD ORIGIN MATERIAL - THE SINE QUA NON OF BOTANIC GARDEN COLLECTIONS?
}

\author{
JAMES CULLEN ${ }^{*}$
}

Botanic gardens make great claims for their content of 'wild origin material' for use in research, education and conservation. But the material included under this heading is very diverse in its nature and origin, covering a broad spectrum of histories. Various types of wild origin material are distinguished, and the effects of these distinctions on botanic gardens record systems briefly considered.

When considered in terms of its origin, plant material in the living collections of botanic gardens is a very mixed bag indeed. Plants can have been bought in nurseries, given by supporters or friends, obtained from other botanic gardens through seed- or plant-exchange, or raised from material collected by plant collectors in the field. With every kind of origin, and for every plant, there must be more or less documentation to show at least how the plant came to be in the botanic garden in the first place (I am assuming here that if such documentation is not retained, then the main qualification for the garden in question to be considered 'botanic' is lacking). This documentation may consist of original paper records, or it may be computerised, but however it was received and is retained, it will form part of the garden's record system.

From the point of view of scientific research, study and conservation, the information about the various individual accessions is particularly important when the plant(s) in question are thought to have originated directly from, and are properly representative of, some population in the wild - that is, the plants are there as 'wild origin material'. With very good reason, botanic gardens make claims that the holding of such material is one of the main justifications for their existence, and one of the main distinctions between them and gardens, whether private or public, which are purely or mainly for amenity purposes. The holding and proper maintenance of such plants and the records relating to them (curation) is one of the major activities of botanic gardens, taking up important facilities and considerable amounts of staff time.

Curation in these terms is a matter of some complexity, requiring a meticulous approach to both the plants and the records relating to them. It is clearly important that the plants should not be confused with others (as can easily happen with seedlings or with young cuttings - the old gardener's principle of laying these out in cold frames left to right and top to bottom, with only the first pot of each batch labelled is a recipe for curatorial disaster), that their labelling is careful and properly persistent (i.e. that the display for public information is not the only identifier of the plant's origin), and carefully done by the label-maker, particularly in the matter of the copying of numbers, which are so easily misread or transposed, that the changes in the plant's condition, locality and situation are communicated to the records system immediately, and that the records are properly maintained (again, the miscopying of numbers is often a cause

\footnotetext{
* Dr Cullen is Director of the Stanley Smith (UK) Horticultural Trust. Prior to that, he was Assistant Keeper at the Royal Botanic Garden Edinburgh.

Addresss: PO Box 365, Cambridge CB2 1HR
} 
of incorrect attribution of documentation details). Much information about these matters is available in Leadlay \& Green (1998), especially chapters 3, 4 and 7.

Because the information that is available about the origins of particular plants can be very variable, it is necessary to understand that the category 'wild origin material' covers an enormous range of possibilities, which have greater or lesser value in terms of the potential scientific and conservation uses of the plants in question. In much discussion about such material, this variation is largely forgotten, and the whole is lumped together as being self-evidently different from the plant material without any such origin; this means that differences in the scientific and conservation value and status of the plants are often overlooked because all the material is treated in the same way. The information that is relevant to a particular wild-collected plant is originally provided by the person who first collected it in the wild. This information may be extremely basic, e.g. 'Turkey' or 'Colombia', or even 'collected in the wild' (without any further details), or it may be much fuller, including details of the collecting locality with some precision, notes on the material collected, date, habitat, etc. and collector's number (which, in theory, will stay with the plant in cultivation).

With the most careful collectors there may well also be herbarium specimens from the same individual plant from which the introduced living material was derived (seed, cuttings, etc.), both in flower and in fruit, also with the same or at least cross-referenced collectors' numbers.

The last described is the ideal kind of collection: the occurrence of herbarium specimens of the original material allows for comparison of material cultivated under the same (or cross-referenced) collector's number to ensure that, at the very least, it belongs to the same taxon (species, subspecies, varietas, forma) as the original material. If the original material was introduced to cultivation as seed, then some allowance must be made for natural variability within populations when making the comparison between the wild and the cultivated, whereas this is not so important if the original material was introduced as plants, cuttings or scions.

All this is particularly valuable if the plants themselves are long-lived (mainly shrubs or trees). The most notable collections of this type are those made by George Forrest on his nine expeditions to western China and adjacent areas. The seed of Rhododendron that Forrest introduced was collected by him or his Chinese co-workers from plants that were labelled earlier in the year, and herbarium material of both the flowering and fruiting plants was collected and preserved. This herbarium material (over 2,000 sheets of Rhododendron) is in the herbarium of the Royal Botanic Garden Edinburgh, and makes possible a check on whether or not cultivated material has diverged from the original by one means or another. A large batch of living 'wild origin' material of Rhododendrons supposedly collected by Forrest (and Joseph Rock, see below), coming in to the Edinburgh garden from other garden collections in the mid 1970s was found, by the above test, to be wrong in slightly more than $50 \%$ of cases, showing that curation had been a mixed blessing over the previous 40 or 50 years. This type of collection is the product of years-long collecting expeditions, such as those carried out by Forrest and by Joseph Rock (who lived for long periods in the areas in which he collected) and these are no longer possible, except for natives of the areas in question.

Such collections are particularly important for long-lived, woody plants. They are also important for shorter-lived plants (mainly herbaceous perennials and alpines), 
though there are some pitfalls with these. Forrest collected many species of Primula with the same attention to detail that he gave to Rhododendron, and these were introduced to gardens under his collecting numbers. However, the persistence of these plants is not great, and seed collected from such Forrest material in gardens cannot properly be considered to belong to the same collection, and hence, plants raised from such seed should not bear the collector's number; obviously, in the records it should be noted that such plants are 'from seed of a Forrest collection'; over the years, many generations of such plants may be raised and it is a matter of judgement when the infinite regress takes over and the plants are no longer regarded as being of wild origin in any significant way.

I have not seen this problem arise with Primulas, but, when I came into scientific horticulture in 1966, many gardens were still growing plants labelled Meconopsis grandis Ludlow \& Sherriff 600 (see Fletcher, 1975). This collection, made at Sakden in Bhutan in 1934, as shown by the herbarium specimens (at The Natural History Museum and Edinburgh), is of a plant which is monocarpic with a 5-8 year life cycle. Hence, even on the best assumption, the plants I saw were at least four seed generations away from the original and on the worst six or seven. Knowing the potentiality for Meconopsis to hybridise in gardens, it is not surprising that the material grown in the late 1960s under this number was astonishingly variable. Clearly, in a case like this, the link to the genuine wild origin material is very tenuous after a couple of generations and, though worth recording, is not very significant. The 1960s material was not in any way 'wild origin material' even though this status was claimed for it by the appearance of the collectors' number on the labels and in the records. Such claims are spurious, and should be avoided as they cast doubt on all other claims for the significance of the wild origin material.

Somewhat similar problems may arise with woody material, as genuine original plants are propagated by cuttings, grafts or layers. The plants that result from such procedures should be genetically similar to their origins, and therefore can be considered as still proper wild origin material on the same basis as the originals. However, it must be remembered that, as cuttings/scions/layer-generations accumulate, so can genetic anomalies (polyploid sectors or shoots, somatic mutations, sports). Here again, comparison with the original herbarium material is very important in maintaining the purity of the wild origin concept. This is even more the case if the woody plant in question has been propagated by seed from a cultivated plant of definitely known wild origin. With genera like Rhododendron, in which hybridisation in gardens is the rule rather than the exception, there is no possibility that such plants can be thought of as being of wild origin in any meaningful way, even if they do seem to appear to be of the same taxon as the original herbarium material.

When no herbarium material was collected by the original collector introducing seed or other propagules, such checking back is not really possible. All that we have is the living material produced from the introduction. Unless proved otherwise, we have to assume that this material is what it purports to be - the 'same' as that from which the original collection was made. In the first generation this is probably safe, but as further propagation takes place, the possibility for errors increases; again, there must come a point at which it is not possible to claim that material several generations down the line from the original is genuinely 'wild origin'. It clearly should be recorded as having 
originated by propagation from the introduced material, but judgement is required as to how long the plants can be claimed to 'be' the original.

All of this discussion points up the importance of the maintenance of detailed propagation records as part of a botanic garden's record system. Unfortunately, such detail was often not recorded in the past, and we are uncertain, even with Rhododendron, how many generations the plants we see today are from their origins some may indeed be the original plants, now 50-100 years old, whereas others may be from propagations since then. Fortunately, in recent years the importance of such records has been realised, and many gardens are now maintaining details of propagation as a routine part of record keeping.

From what I have already discussed, it is clear that the idea of 'wild origin material', and its associated higher value for botanic gardens, is not simple and is often unclear. The following table (Table 1) indicates some of the categories that can be found in any botanic garden collection, listed in a suggested priority order.

TABLE 1. Categories of wild origin material in botanic gardens, listed in priority order

\begin{tabular}{|c|c|c|c|c|}
\hline $\begin{array}{l}\text { Material (plant, } \\
\text { seedling, cutting, } \\
\text { scion, seed, meristem } \\
\text { samples) }\end{array}$ & $\begin{array}{l}\text { Herbarium specimens } \\
\text { of wild plant } \\
\text { (flowering and/or } \\
\text { fruiting) }\end{array}$ & Collecting details & $\begin{array}{l}\text { Propagation } \\
\text { method }\end{array}$ & Grade \\
\hline \multirow{4}{*}{$\begin{array}{l}\text { 1. Directly from wild } \\
\text { plant or wild } \\
\text { population }\end{array}$} & \multirow[t]{2}{*}{ Collected } & Full & NA & $\mathrm{A}$ \\
\hline & & $\begin{array}{l}\text { Basic, e.g. country } \\
\text { only }\end{array}$ & NA & $\mathrm{B}$ \\
\hline & \multirow[t]{2}{*}{ Not collected } & Full & NA & $\mathrm{C}$ \\
\hline & & $\begin{array}{l}\text { Basic, e.g. country } \\
\text { only }\end{array}$ & NA & $\mathrm{D}$ \\
\hline \multirow{8}{*}{$\begin{array}{l}\text { 2. From a cultivated } \\
\text { plant qualified under } 1 \\
\text { above }\end{array}$} & \multirow[t]{4}{*}{ Collected } & \multirow[t]{2}{*}{ Full } & Vegetative & $E$ \\
\hline & & & Seed* & $\mathrm{F}$ \\
\hline & & \multirow{2}{*}{$\begin{array}{l}\text { Basic, e.g. country } \\
\text { only }\end{array}$} & Vegetative & $\mathrm{G}$ \\
\hline & & & Seed* & $\mathrm{H}$ \\
\hline & \multirow[t]{4}{*}{ Not collected } & \multirow[t]{2}{*}{ Full } & Vegetative & I \\
\hline & & & Seed* & $\mathrm{J}$ \\
\hline & & \multirow{2}{*}{$\begin{array}{l}\text { Basic, e.g. country } \\
\text { only }\end{array}$} & Vegetative & $\mathrm{K}$ \\
\hline & & & Seed* & $\mathrm{L}$ \\
\hline
\end{tabular}

In part of the column headed 'Propagation method', the entry 'seed' is sometimes asterisked: this means that in these cases plants propagated from seed should not be regarded as of wild origin unless the plant in question is known to be either apomictic, obligately self-fertilising, or, if not wind-pollinated, the only one of its kind for some distance. The column for 'Grade' shows the value and importance of the collection referred to, with $\mathrm{A}$ as the highest grade, $\mathrm{L}$ as the lowest. I must stress that these grades are not meant to be set in stone, and are merely my assessment of the comparative values of the different kinds of collections; however, the possibility of assigning these grades (or grades from a system similar to this) to individual collections is relatively simple, and would make a sensible addition to any record system.

As scientific research on plants develops, together with attempts to achieve the aims of target 8 (viii) of the Global Strategy for Plant Conservation (Secretariat of the Convention on Biological Diversity, 2002) - that "60 per cent of threatened plant species [should be] in accessible ex situ collections, preferably in the country of origin 
and 10 percent of them included in recovery and restoration programmes" by 2010 , the claims made by botanic gardens that at least some of the material they hold is of wild origin and suitable for scientific and conservation purposes, will be tested to the full, and it is important that gardens rise to the challenge, providing the properly documented material that will be needed.

\section{REFERENCES}

FLETCHER, Harold F. (1975). A Quest of Flowers. Edinburgh University Press, Edinburgh.

LEADLAY, E. \& GREENE, J. (1998). The Darwin Technical Manual for Botanic Gardens, BGCI, London.

SECRETARIAT OF THE CONVENTION ON BIOLOGICAL DIVERSITY (2002). Global Strategy for Plant Conservation. Secretariat of the Convention on Biological Diversity in association with Botanic Gardens Conservation International, Montreal, Canada. 
